\title{
A REITERAÇÃO COMO MECANISMO DE GESTÃO DO TEMPO PELA CRIANÇA*
}

\author{
Eduardo Oliveira Sanches ${ }^{1}$
}

\begin{abstract}
RESUMO: Esta pesquisa, de natureza teórica, teve como objetivo refletir sobre o fenômeno da gestão do tempo realizada pela criança, com base na noção de reiteração, no contexto da Sociologia da Infância. A reiteraçáo, como recurso de gestáo do tempo pela criança, permite a criação de um lugar operacional entre a fantasia e o real que libera a ação da criança e, assim, facilita que ela tenha experiências formativas nas relaçóes que trava com o ambiente social. Ao repetir no brincar os fatos vividos, a criança organiza sua percepção qualitativa e quantitativa do tempo. Por meio da reiteração, a criança realiza uma temporalidade de experimentaçáo do mundo.
\end{abstract}

Palavras-chave: Infância. Reiteração. Cultura infantil. Gestão do tempo. Sociologia da infância.

\section{THE REITERATION AS A CHILD TIME MANAGEMENT MECHANISM}

ABSTRACT: This theoretical research aimed to reflect on the phenomenon of time management performed by the child, based on the notion of reiteration, in the context of the Sociology of Childhood. The reiteration, as a resource of time management, allows the creation of an operational place between fantasy and reality that releases the child's action and facilitates formative experiences in their relations with the social environment. By repeating the real facts in games and plays, the child organizes his/her qualitative and quantitative perception of time. Through reiteration, he/she performs a temporality of world experimentation.

Keywords: Childhood. Reiteration. Child culture. Time management. Sociology of childhood.

\footnotetext{
*Projeto da pesquisa a que se vincula o artigo - "Cultura da criança e modernidade: experiência e infância em Walter Benjamin”. Fonte de financiamento: Fundação de Amparo à Pesquisa do Estado de São Paulo (FAPESP), Processo no 2013/21152-3, e Coordenação de Aperfeiçoamento de Pessoal de Nível Superior (CAPES), Processo no BEX 7915/14-4.

${ }^{1}$ Universidade Estadual de Maringá - Maringá (PR), Brasil. E-mail: eduardo.uem@hotmail.com DOI: 10.1590/ES0101-73302019189816
} 


\title{
LA REITERACIÓN COMO MECANISMO DE GESTIÓN DEL TIEMPO POR EL NIÑo
}

\begin{abstract}
RESUMEN: Esta investigación de naturaleza teórica tuvo como objetivo reflexionar sobre el fenómeno de la gestión del tiempo realizado por el niño, a partir de la noción de reiteración, en el contexto de la Sociología de la Infancia. La reiteración, como recurso de gestión del tiempo por el niño, permite la creación de un lugar operacional entra la fantasía y el real que libera la acción del niño y, así, facilita que ella tenga experiencias formativas en sus relaciones con el ambiente social. Al repetir en el jugar los hechos vividos, el niño organiza su percepción cualitativa y cuantitativa del tiempo. Por medio de la reiteración, el niño realiza una temporalidad de experimentación del mundo.
\end{abstract}

Palabras clave: Infancia. Reiteración. Cultura infantil. Gestión del tiempo. Sociología de la infancia.

\section{Introdução}

A

escolha do recorte proposto neste estudo justifica-se pelo fato de as abordagens realizadas no contexto das produçóes da Sociologia da Incia na atualidade. Apesar de ser um campo do conhecimento relativamente novo e ainda em construção, tem contribuído, desde o seu nascedouro, para pensar a infância e os problemas afetos a ela no interior do discurso sobre a educação. Assim, considera-se importante que os profissionais da educação examinem as contribuiçóes da Sociologia da Infância para pensarem os novos paradigmas sobre um dos principais sujeitos envolvidos no processo da educação escolar: a criança.

Temos por objetivo neste estudo refletir sobre os mecanismos de gestão do tempo infantil feitos pelas próprias crianças, sob a perspectiva do conceito de reiteração. Visto os poucos estudos com ênfase na reiteração, eixo estruturante do conceito de cultura infantil para a Sociologia da Infância, e tendo em vista o crescente processo de institucionalização da infância — primeiramente pela compulsoriedade da escolarização na modernidade e posteriormente pela adoção do regime de tempo integral nas escolas na modernidade tardia - , necessitamos conhecer melhor o funcionamento da gestão dos tempos infantis feitos pelas próprias crianças (SARMENTO, 2004; SANCHES; SILVA, 2016; 2018b). Tal conhecimento contribui para organizar tempo e espaço escolares de modo a favorecer a agência infantil como parte do desenvolvimento da criança.

Esse tipo de observação das formas da vida infantil, por exemplo, pode apoiar futuras mudanças no modelo escolar brasileiro para que receba de maneira 
mais apropriada as necessidades das crianças do século XXI. Na França, por exemplo, o conhecimento sobre aspectos como esse possibilita coordenar a escola e a comunidade como parceiras da criança no sentido da gestão dos tempos infantis. Assim, há estruturas urbanas como equipamentos de lazer, museus e parques totalmente adaptados para uma melhor experiência da criança com a cidade ${ }^{1}$. Isso possibilita também que a integralidade do tempo escolar não seja, necessariamente, percorrida no interior das escolas. Com frequência, observam-se pelas ruas e pelos metrôs grupos escolares a passeio e em espaços conforme os citados, como parte do currículo escolar. Isso oferece às crianças outras formas e oportunidades de aprender a gestão do próprio tempo, tanto na escola como fora dela, em um contato fecundo e vivo com a cidade.

Nesse sentido, esperamos, com este estudo, contribuir para ampliar as reflexóes sobre a reiteração, para melhor compreensão dos fenômenos infantis ligados à gestão do tempo feito pela criança. Como a reiteração é um dos conceitos estruturantes das culturas infantis, o que aqui se propóe pode ser de muita utilidade não apenas para a educação como para os estudos contemporâneos sobre a infância.

\section{Do in-fans ao protagonismo infantil: um breve percurso sobre a identidade da infância}

A Sociologia da Infância é relativamente recente, visto que se constitui enquanto campo teórico entre as décadas de 1980 e 1990. Em 1989, "com a aprovação pelas Naçóes Unidas da Convenção dos Direitos da Criança, as crianças viram consagradas de forma suficientemente clara e extensa um conjunto de direitos fundamentais, próprios e inalienáveis" (SARMENTO; PINTO, 1997, p. 11). Após a promulgação do documento citado, Sarmento e Pinto (1997) destacam o Congresso Mundial de Sociologia como um marco importante para a sistematizaçáo do campo, em que, segundo eles, discutiram-se pela primeira vez os processos de socialização da criança na sociedade contemporânea. Os autores relatam ainda que, desde o congresso citado, houve um crescimento exponencial na internacionalização das pesquisas sobre a infância no qual a multidisciplinaridade e interdisciplinaridade foram fundamentais para a estruturação da área de conhecimento (QUINTEIRO, 2002; SARMENTO; PINTO, 1997; SARMENTO, 2005). "Daí em diante, os estudos passaram a contribuir para definir correntes de pensamento, propostas de abordagens metodológicas e a delimitar conceitos que consolidaram a Sociologia da Infância enquanto área do conhecimento" (SANCHES; SILVA, 2016, p. 508-509).

A ideia de infância tem a marca da negação em sua origem em razão do modo como ela foi vista na maior parte de processo histórico que deteminou a instituição do seu estatudo social (SARMENTO, 2005). Na maior parte dos regis- 
tros anteriores à Sociologia da Infância, a criança fora analisada a partir do ponto de vista da incompletude, da incapacidade e do inacabamento como ser. Sarmento (2006) evidencia essa perspectiva valorativa e como ela ainda perdura na atualidade, apesar de todos os avanços sobre a compreensão social da criança. $\mathrm{O}$ autor cita como exemplos "a impossibilidade de votar; a não participação política com a expressão da opinião e a visão infantil sobre os problemas e a gestão pública; o planejamento das cidades com os espaços adaptados para a infância" (SANCHES; SILVA, 2016, p. 510).

Para Sarmento (2004, p. 19), “a consciência social da existência da infância [...] é, com efeito, algo que começou a emergir com o Renascimento, para se autonomizar a partir do século das luzes”. O sociólogo afirma que a infância é um "entre-lugar", pois é demarcado por dois modos viventes distintos: aquele pautado pelo olhar do adulto, e outro que passa a ser reivindicado pela e para a criança e que são vividos por ela no presente. $\mathrm{O}$ "entre-lugar" é o limiar entre o passado e o futuro das ideias sobre a infância, portanto "pre-disposto nas suas possibilidades e constrangimentos pela História” (SARMENTO, 2004, p. 19). A Sociologia da Infância se opóe a tal modo de atribuir valor à condição da infância e entende que toda criança é competente se levada em conta a história das experiências vividas por ela (SARMENTO; MARCHI, 2008; SANCHES; SILVA, 2016 ; 2018b). Assim, a infância não é considerada uma idade de transição para outra fase da vida, um ser do devir, contudo, segundo afirma Sirota (2001), é parte componente da cultura e da sociedade.

Embora ignorada até pouco tempo, há registro de uma sociologia e antropologia da infância datada dos anos de 1930, como é possível verificar em um ensaio de 1937 do sociólogo e antropólogo francês Marcel Mauss, intitulado "Três observaçóes sobre a sociologia da infância". Nele, evidencia-se uma Sociologia da Infância ainda como campo incipiente, que, no entanto, já se colocava como problematizadora acerca da vida da criança. No ensaio, o pensador propóe três problemáticas iniciais para se pensar a infância: a infância como meio social para a criança; os problemas geracionais; e a questão relativa às técnicas corporais (MAUSS, 2010).

Para Sirota (2001, p. 10), "a emergência do objeto infância questiona os modos de abordagem, não só no plano teórico como também no disciplinar ou metodológico, o que obriga a uma recomposição de campos, tanto entre disciplinas das ciências sociais quanto entre subdisciplinas". Tal quadro só se modifica após a infância ressurgir, no início dos anos de 1980, como uma problemática evidente e recorrente. Por um lado, segundo Sirota (2001), por meio de uma visão durkheimiana, a criança é considerada objeto de socialização, lugar para se inscrever a cultura, como um ser passivo que precisa ser preenchido via escola, família, trabalho, enfim. Nessa perspectiva,

a sociologia em geral, particularmente a sociologia da educação, seja ela de língua francesa ou inglesa, permaneceu durante 
muito tempo implicitamente circunscrita a essa definição durkheimiana, desenvolvendo em perspectivas autônomas de pesquisa, diferentes olhares sobre a infância, configuradas segundo os modos de apreensão institucional do objeto social. Estes são, pois, os pontos de partida do apagamento da infância ou de sua marginalização (Qvortrup, 1994; Corsaro, 1997) como objeto sociológico, contrariamente às proposiçóes de Mauss. A infância será essencialmente reconstruída como objeto sociológico através dos seus dispositivos institucionais, como a escola, a família, a justiça, por exemplo (SIROTA, 2001, p. 9).

Por outro lado, a reconstrução do olhar sobre a infância inaugura um novo foco, no qual ela passa de objeto de socialização a ator social, tendo valorizado sua capacidade como agente, seu protagonismo. A socióloga ainda menciona as contribuiçóes da historiografia, fundamentalmente, Ariès (1981), que contribuiu de modo decisivo para precisar uma ideia de infância como categoria social enquanto tese. $\mathrm{O}$ fato é considerado importante, pois ele ajuda a fortalecer o argumento sobre o protagonismo infantil, na contramão da Sociologia Clássica de Durkheim que, com frequência, de acordo com Sirota (2001), reduzia a relação de socialização das crianças nas instituiçóes como um trabalho de incorporação de normas, princípios e valores. Para a autora, é a constituição de um pensamento em oposição ao da criança passiva e as problematizaçóes decorrentes dessa nova noção que se constituíram as primeiras filigranas denominadas de Sociologia da Infância.

Enquanto organização do campo, outro fator a se considerar, segundo nos alerta a socióloga, é a ideia de tomar a infância como grupo social em si, trazendo, em seu interior, traços específicos das idades da infância. "Assim se retoma a proposição de Mauss de considerar a infância como um meio social para a criança, desse modo, articulando essa abordagem à sociologia geral”. Em tal contexto, afirma a autora, "trata-se, no âmbito dessas contribuiçóes, de tomar com seriedade esse ator social que é a criança, interrogando-se sobre os quadros teóricos disponíveis ou necessários" (SIROTA, 2001, p. 11). A necessidade de ampliar o arcabouço teórico-metodológico provocou uma busca basilar em diversos eixos do conhecimento, dentro e fora da sociologia, que resultaram em desvios da Sociologia Clássica, contribuindo para a estruturação da Sociologia da Infância (SARMENTO, 2013).

A consolidaçáo do campo como expediente acontece por meio do estabelecimento de categorias com as quais se poderia então pensar a criança nas relaçóes com a sociedade. Nesse sentido, a era moderna outorga à criança a escola como o local privilegiado de sua ação, e a família o centro do seu cuidado. Sarmento (2011) vai chamar a atenção sobre como a ideia da escola como ofício da criança emerge e, a partir dele, a sistematização de certos princípios da pesquisa com crianças. A ideia de "ofício de criança" e de "ofício de aluno" demonstra o efeito das instituiçóes para crianças que criam normas para o desempenho social 
delas. Em tais ambientes sociais, são efetivados mecanismos de socialização estruturados segundo a visão adulta sobre a infância, e, dessa maneira, uma relação de socialização prescritiva dos parâmetros sócio-histórico-culturais que direcionam tempo e espaço na vida infantil.

O ofício de criança "é um conjunto de comportamentos e acçóes que se espera que a criança desempenhe - o qual foi inicialmente concebido como 'ofício de aluno'" (SARMENTO, 2011, p. 586). [...] O aluno, tem por ofício, de tomar a forma (no sentido de se deixar formatar), adquirir a cultura escolar deixando de lado, entre parêntesis ou de modo definitivo, a sua cultura de origem, quando incompatível com a cultura escolar, ou a cultura gerada e reproduzida nas relaçóes com os seus pares: as culturas da infância - e ajustar-se à disciplina do corpo e da mente induzida pelas regras e pela hierarquia dos estabelecimentos de ensino que frequenta (SARMENTO, 2011, p. 589).

Todavia, as instituições escolares e os reformatórios são igualmente questionados pela infância aprisionada e educada por elas. "A criança reage ao modelo de processo civilizatório que lhe é imposto e, nesse instante, ela náo reproduz e sim reinterpreta a realidade desses locais, sendo, assim, protagonista do próprio crescimento e ampliação de habilidades" (SANCHES; SILVA, 2016, p. 511). Com isso, a infância, enquanto meio para a criança, conforme sugere Mauss, ganha nova vitalidade. E, assim, parte importante "dos primeiros sociólogos que se interessam pela criança passam deliberadamente de uma sociologia da escolarização a uma sociologia da socialização. Eles se atêm à socialização primária visando a essa população infantil tanto como ser em devir quanto como ator de sua própria socialização" (SIROTA, 2001, p. 18). Isso trouxe a necessidade de desenvolver meios de pesquisa que transferissem a fala para a criança para que ela pudesse nomear a infância a partir de seu ponto de vista (SARMENTO; MARCHI, 2008). Nesse traço, evidencia-se outra característica, a da criança como um ser também no presente e não apenas como ser do devir.

A criança como ator na ação social é, portanto, uma linha mestra para se pensar a infância nessa forma de registro. $\mathrm{O}$ protagonismo infantil implica a ideia não de uma criança da falta, o in-fans, mas de uma que, por meio de sua ação no mundo, produz e dá sentido a ele. Isso representa a legitimação da capacidade de produção simbólica da criança, segundo Sarmento e Pinto (1997). Sirota (2001, p. 22) coloca o quadro da seguinte forma:

A questão aqui proposta refere-se à construção das competências políticas infantis num quadro preciso, a escola primária. Como aqueles que são considerados como não tendo ainda uma palavra política podem construir suas competências? O que então a noção de "competências políticas" pode oferecer para esclarecer esse processo e erigir a criança como ator no interior de um 
sistema explicativo sociológico? A noção de competências políticas sendo entendida como a de "capacidades para organizar uma vida social ordenada com valores compartilhados" mediante o aproveitamento da experiência, tanto do pátio de recreação como da sala de aula, coloca em discussão formas elementares ou ordinárias da cidadania e do elo civil.

Em última instância, a análise do protagonismo infantil, para a autora, converge para um importante aporte metodológico para as pesquisas com crianças. Ao considerá-las para além de meras reprodutoras ou seres do devir, viabilizam-se caminhos para compreender a construção de valores éticos e morais que são constituídos por meio do fazer infantil, como experiência social e política, numa espécie de microssociedade infantil - a comunidade escolar, ou suas trocinhas (FERNANDES, 2004).

A comunidade que se forma no âmbito da escola é composta de sujeitos de distintas gerações. Há crianças de mesmo núcleo geracional, o que configura a relação de pares; ocorre também a relação intergeracional, entre crianças e adultos; e, até entre os adultos, há os mais jovens e os idosos, conjugando mais uma situação geracional da comunidade escolar. Em tal perspectiva, a tentativa é mostrar como considerar a criança em um sentido pleno da ação social, permitindo ressignificar as trocas simbólicas e compreendendo seus processos, constituiçáo e resíduos. Sarmento (2006) propóe que o estudo da criança como categoria geracional deve ser proposto a partir de algumas diretrizes. Primeiramente, ao compreender a infância em si mesma, o critério da homogeneidade prevê que há certas características que unem em um eixo comum todas as crianças, como a noção moderna, mas bastante popular, de que "lugar de criança é na escola". Em um segundo momento, igualmente importante, constata-se a heterogeneidade, que implica dizer que, mesmo sendo um dado coletivo de crianças pertencentes ao mesmo período geracional, elas também são diferentes e podem ser distribuídas por categorias sociais distintas, tais como sexo, classe social, gênero, faixa etária, origem étnica e religiosa etc.

A geração não dilui os efeitos de classe, de género ou de raça na caracterização das posiçóes sociais, mas conjuga-se com eles, numa relação que não é meramente aditiva nem complementar, antes se exerce na sua especificidade, activando ou desactivando parcialmente esses efeitos [...] a geraçáo consiste num grupo de pessoas nascidas na mesma época, que viveu os mesmos acontecimentos sociais durante a sua formação e crescimento e que partilha a mesma experiência histórica, sendo esta significativa para todo o grupo, originando uma consciência comum, que permanece ao longo do respectivo curso de vida. A acção de cada geração, em interacção com as imediatamente precedentes, origina tensões potenciadoras de mudança social (SARMENTO, 2005, p. 363-364). 
Sob essa ótica, a infância necessita ser estudada e articulada aos elementos que a homogeneízam e àqueles que as tornam diferentes de si mesmas, das outras geraçóes de crianças e das outras categorias geracionais, como adultos e idosos. Entender a infância como categoria social do tipo geracional é compreendê-la no espaço da determinação histórica, dotando de certa identidade uma geração. Por exemplo, a geração das crianças dos anos de 1960 apresenta características próprias que a diferencia da geração de crianças dos anos de 1980, no entanto ambas são determinadas pela categoria social infância. Desse modo, a geração é uma variável que está associada aos aspectos das dinâmicas populacionais e econômicas de uma sociedade. No contexto brasileiro atual, poderíamos exemplificar problematizando o impacto do programa Bolsa Família nas vidas das crianças pobres. Que efeitos o projeto de distribuição de renda tem gerado a longo prazo na vida das crianças dessa geração, se comparada à das de geraçóes passadas? Como ela tem sido inserida no mercado consumidor? Tais questóes revelam que, de modo geral, "a infância é independente das crianças; estas são os actores sociais concretos que em cada momento integram a categoria geracional; ora, por efeito da variação etária desses actores, a 'geração' está continuamente a ser 'preenchida' e 'esvaziada' dos seus elementos constitutivos concretos" (SARMENTO, 2005, p. 364).

Esse processo de constante renovação das geraçóes de crianças acaba por contribuir para que a própria noção de infância ganhe movimento e transformação constante, pois a criança que é pautada pelos adultos hoje pautará a infância do amanhã. Nessa relação de troca, a cada geração, algo novo surge ou emerge do passado com sentido renovado no presente, caracterizando as relaçóes entre adultos e crianças como um elo que faz movimentar a própria ideia da infância. As variáveis que acomodam essa transformação, afirma Sarmento (2005), são diferentes em cada momento histórico, oscilando o peso de cada uma delas na determinação das vidas das crianças por meio da infância que se pensa para elas em cada época. "Em suma, o conceito de geração não só permite distinguir o que separa e o que une, nos planos estrutural e simbólico, as crianças dos adultos, como as variaçóes dinâmicas que nas relaçóes entre crianças e entre crianças e adultos vai sendo historicamente produzido e elaborado" (SARMENTO, 2005, p. 366).

\section{Reproduzir, interpretar, criar}

Segundo Sarmento (2005), a infância moderna caracteriza-se, fundamentalmente, em separar as crianças do adulto e institucionalizá-las. Neste caso, afirma ele, criaram-se os primeiros sentimentos sobre a infância, conforme Ariès (1981) significa o termo. No mesmo percurso, a instituição da infância moderna é acompanhada de uma escola para massas. A infância moderna determina a todas as crianças, como ofício, o trabalho de ser aluno em conjunto com a noção emergente do que é ser criança sob o signo desse estatuto. A escola separa-a do dia a dia das 
famílias e se torna um símbolo moderno do ritual de passagem que fará da criança o futuro da nação. Apesar de ainda na atualidade não existir a universalização dessa infância como acesso para todas, ela se torna um paradigma, um direito da criança e um dever da sociedade. Nesse sentido, por mais que haja certa convergência sobre o que é a infância, existem muitas outras infâncias para além dessa. As diferentes possibilidades formativas produzem espaços também distintos no que diz respeito às experiências, o que muda as crianças e as diferencia em cada contexto.

A partir da conjuntura descrita, o conceito de reprodução interpretativa (CORSARO, 2002) contribui para compreender a forma de interpretar a ação da criança. A ideia que se faz por meio dessa noção é a de que a criança não apenas reproduz o que ele recebe do mundo adulto como a herança cultural, para, além disso, na relação que elas estabelecem entre si enquanto pares, evidenciarem uma capacidade em interpretar e também transformar tal herança cultural (SARMENTO; MARCHI, 2008; SANCHES; SILVA, 2018a). Diante disso, o termo "reprodução interpretativa" compreende a capacidade da criança de incorporar e de redimensionar de modo criativo o ambiente e os elementos culturais aprendidos nas relaçóes entre as crianças e delas com os adultos.

Esse conceito descrito e nomeado por Corsaro (2002) é constituído de meio da aproximação e da tensão entre três áreas do conhecimento: a Sociologia, a Antropologia e a Psicologia. A abordagem consequente desse processo resulta em uma forma nova de interpretar a socialização na infância. Parte-se do pressuposto de que a "criança começa a vida como seres sociais inseridos numa rede social já definida e, através do desenvolvimento da comunicação e da linguagem em interação com outros, constroem os seus mundos sociais" (CORSARO, 2002, p. 114). Nessa vertente, esse mundo pequeno inserido no grande, segundo a orientação do conceito, nunca é uma reprodução exata da cultura adulta apropriada pela criança, e sim uma apropriaçáo criativa daquilo que está em seu entorno. Esse aspecto dito criativo no modo de reinterpretar a cultura adulta é que dá o sentido ao conceito; a criança reproduz aspecto inerente ao mundo em seus processos de socializaçáo, no entanto reinterpretando os elementos culturais apropriados, expressando a seu modo. Aliás, Corsaro (2002, p. 115) afirma que a própria criança e seus fazeres acabam se tornando parte da cultura adulta, isto é, "contribuem para a sua reprodução através das negociações com adultos e da reprodução criativa de uma série de culturas de pares com as outras crianças".

No ensaio intitulado "A Reprodução Interpretativa no Brincar ao 'Faz de Conta' das Crianças", o autor faz um estudo de cunho etnográfico, visando testar a hipótese que remete ao conceito de representação interpretativa. No estudo, é analisado o contexto de jogos sociodramáticos, no qual se compara o conteúdo simbólico das representaçóes sociais entre dois grupos de crianças de classes sociais distintas. A problematização que estabeleceu o foco dado para as observaçóes e as análises posteriores foi: 
Como é que as crianças relacionam ou articulam as características locais dos desenrolar do brincar ao "faz-de-conta" com as suas concepçóes do mundo adulto. Esta articulação permite às crianças apropriarem-se de aspectos da cultura dos adultos que depois usam, refinam e expandem (CORSARO, 2002, p. 118).

Ao final, segundo afirma o pesquisador, podem ser verificadas ao menos três situaçóes. A primeira foi de que a cultura adulta serviu para compor um cenário de coerência na brincadeira realizada no contexto de pares das crianças. Por outro lado, como segunda conclusão, a fantasia da criança traz consigo certa dose de colorido que realça ou extrai da realidade aspectos que asseguram o interesse da criança em permanecer na atividade. E, em um terceiro núcleo de consideraçóes, o autor evidencia que as crianças não apenas recriaram o ambiente possível do fazer diário oriundo das relaçóes estabelecidas com a cultura adulta, mas, por meio do jogo sociodramático, elas conseguiram desenvolver problematizaçóes "através das quais elas confrontaram as estruturas objectivas ou as circunstâncias da vida quotidiana" (CORSARO, 2002, p. 132). O jogo simbólico, portanto, mostra-se como meio e produto do fazer infantil, resultado de inúmeras reproduçóes e revisão do mundo adulto.

\section{Breves considerações sobre as culturas infantis}

Estudos como os de Corsaro (2002) são utilizados, no contexto da Sociologia da Infância, para sustentar a hipótese de as formas culturais produzidas pelas crianças apresentarem certa autonomia. Os recursos pelos quais essas formas culturais se estruturam e se desenvolvem estâo centrados em maneiras específicas de comunicação entre crianças que se diferem em forma e conteúdo das relaçôes estabelecidas entre crianças e adultos. Isso demonstra certa autonomia da criança na relação com a cultura hegemônica, adultocêntrica e também a dependência desse ambiente para a criação do que a Sociologia da Infância compreende como cultura(s) infantil(s) ${ }^{2}$. Cohn (2005) afirma que a cultura, ao passar a ser entendida como um sistema simbólico, permitiu afirmar que as crianças sáo produtoras de culturas. Nesse caso, a ideia de passividade da criança diante da cultura pôde ser revista.

A questáo deixa de ser apenas como e quando a cultura é transmitida em seus artefatos (sejam eles objetos, relatos ou crenças), mas como a criança formula um sentido ao mundo que a rodeia. Portanto, a diferença entre as crianças e os adultos não é quantitativa, mas qualitativa; a criança não sabe menos, sabe outra coisa. Isso não quer dizer que a antropologia da criança recente se confunda com análises do desenvolvimento cognitivo; ao contrário, dialoga com elas. A questão, para a antropologia, não é saber em que condição cognitiva a criança elabora sentidos e significados, e sim a partir de que sistema simbólico o faz (COHN, 2005, p. 33-34). 
Esse conceito antropológico de cultura é compartilhado pela Sociologia da Infância. Por cultura da infância, "entende-se a capacidade das crianças em construírem de forma sistematizada modos de significaçáo do mundo e de acção intencional, que são distintas dos modos adultos de significação e de acção" (SARMENTO, 2003, p. 53-54). Em outra definição, as "culturas das crianças são "um conjunto estável de actividades ou rotinas, artefatos, valores e ideias que as crianças produzem e partilham em interacção com os seus pares'" (CORSARO; EDER, 1990 apud SARMENTO, 2005, p. 373). As culturas infantis testemunham o modo como as crianças significam o mundo e dividem suas experiências no contexto de suas relaçôes. As culturas infantis estão, portanto, "relacionadas ao que é produzido pela criança a partir das relaçóes por ela e com ela estabelecidas. Vinculam-se aí os instrumentos do brincar (Spielzengen) ${ }^{3}$, bem como toda forma de interação entre ela e o ambiente que produza significação no contexto geracional no qual ela se insere" (SANCHES; SILVA, 2016, p. 511).

Para Sarmento (2004, p. 13), quatro são os eixos por meio dos quais ele aborda a problemática das culturas infantis: "a interactividade; a ludicidade, a fantasia do real e a reiteração". O recorte que ele propóe justifica-se a partir da necessidade que se criou no meio científico acerca de noçóes que pudessem ajudar a precisar de modo mais claro "a inventariação dos princípios geradores e das regras das culturas da infância”.

A interatividade diz respeito aos vários ambientes e às pessoas com as quais a criança mantém relação. Para o autor, as variáveis das realidades com as quais a criança cria laços contribuem para formar uma identidade multifacetada nos âmbitos social e individual. Nas tarefas diárias, realizadas na escola ou na família, ocorre um conjunto de aprendizagens de modo interativo, por meio do qual a criança compartilha, com outros seres, tempo, espaço, experiências, fantasias e realidades. No contato com outras crianças, é estabelecida a cultura de pares, local privilegiado da aprendizagem no sentido relacional. Ela permite a cada criança se assenhorar do universo em seu redor, produzindo, reproduzindo os mecanismos simbólicos a ele inerentes, ao passo em que inventa e reinventa parcelas de sentido para esse mundo de modo criativo, a partir de uma lógica da infância (SARMENTO, 2004).

Em tal contexto, a ludicidade, segundo eixo de análise do autor, compóe um elemento fundante e sem o qual se torna débil uma noção de cultura infantil.

Com efeito, a natureza interactiva das crianças constitui-se como um dos primeiros elementos fundacionais das culturas da infância. O brincar é a condição da aprendizagem e, desde logo, da aprendizagem da sociabilidade. Não espanta, por isso, que o brinquedo acompanhe as crianças nas diversas fases da construção das suas relações sociais (SARMENTO, 2004, p. 16).

Para Brougère (2002), o ato de brincar se constitui como um lugar de produção cultural privilegiado, o da cultura lúdica, no qual o autor, em al- 
guns momentos, apresenta-a como faceta central para a própria ideia de infância. Ele afirma que a cultura lúdica se constitui como produto da interaçáo social e que ela tem origem na interação entre o bebê e sua figura materna. "Pode-se entáo considerar que através do jogo a criança faz a experiência do processo cultural, da interação simbólica em toda a sua complexidade" (BROUGÈRE, 2002, p. 32), formando-se, em certo sentido, por meio dos recursos lúdicos que compóem as filigranas dos jogos e das brincadeiras.

O terceiro eixo emerge como elemento de união entre fantasia e realidade. A fantasia do real, segundo argumenta Sarmento, é uma faculdade com a qual a criança faz a transposição da realidade mais próxima dela e a "reconstrói criativamente pelo imaginário, seja importando situaçóes e personagens fantasistas para o seu quotidiano, seja interpretando de modo fantasista os eventos e as situaçóes que ocorrem" (SARMENTO, 2004, p. 16). Para o pensador, imaginar a realidade é fundamental como processo que ajuda a compreender os eventos vividos pela criança, por isso esse recurso compóe um traço importante nas culturas infantis, pois permite as crianças terem controle dos processos de aprendizagem do real, na medida das possibilidades de autonomia infantil e em um ritmo aceitável pela mente da criança.

A reiteração, o quarto eixo das culturas infantis, tem relação com a temporalidade da criança que se constitui em um tempo recursivo. Nessa forma de tratar o tempo,

a temporalidade recursiva da criança adquire características que ultrapassam a condição da manipulação do tempo em si. Ela incorpora tendências em que a própria identidade infantil se dissolve e se reintegra. Assim, a criança se apodera, constrói e transforma a si mesma e o entorno dela. O recurso de manipulaçáo do tempo constitui-se, portanto, parte integrante dos processos de apreensão da realidade ou como vivência criativa nas experiências de aprendizagem (SANCHES; SILVA, 2016, p. 513).

Sobre a reiteração, Sarmento (2004) aponta que o tempo da criança é sempre envolto da aura das possibilidades. No ambiente lúdico, o tempo é um recurso administrado pela fantasia do real, portanto recursivo. Nesse contexto ludo-fantástico, a criança negocia consigo mesma e nas relaçóes estabelecidas até onde vai o imaginado e o real. É aí que nasce o mundo de Alice de todas as crianças, na confluência de situações em que o tempo não é um apêndice operacional ou operário do relógio, e sim uma dimensão manipulada pela imaginação.

Nessa condição, o tempo torna-se o recurso capaz de transformar a criança em um ser menor e fazê-la passar pelas portas pequenas da experiência social e, tal qual Alice em seu país das maravilhas, fazê-la maior do que de fato é, antecipando imaginativamente, assim, experiências reservadas a condições futu- 
ras. Nessa condição, a temporalidade recursiva, ou seja, a possibilidade de viver presente, passado e futuro, em um só momento, constitui-se como um dos mais poderosos atributos da reiteração. Essa possibilidade de ser mestre do tempo leva a criança a repetir o jogo ou a brincadeira, carregando, para dentro da atividade lúdica, a parcela da realidade que interessa a ela elaborar. Durante a atividade lúdica, não há linearidade determinada a priori, ou seja, todo o roteiro pode mudar e/ou parar a qualquer momento, segundo a interpretação que a criança faz da realidade que governa o momento lúdico. Está na reiteração uma forma de manipular as variáveis do aprendizado pela criança, no ambiente social em que ela se insere, na relação de pares e nas relaçóes intergeracionais.

\section{Sobre a reiteração como mecanismo de gestão do tempo pela criança}

Como em toda boa viagem, há lugares em que, por um motivo ou outro, escolhemos nos deter por mais tempo. Em nosso itinerário de viagem pela Sociologia da Infância, a ideia de reiteração foi escolhida como expressão desse lugar. Em um contexto histórico como o do século XXI, cuja velocidade de mudança social apresenta-se mais dinâmica e acelerada, em vista de momentos da história anteriores ao capitalismo e mesmo em seu contexto, a gestão do tempo é um importante fator social de impacto na vida das pessoas, imprimindo maior ou menor grau de qualidade de vida aos sujeitos, e isso náo é diferente na vida das crianças. Acontece que a gestão do tempo realizada pelas crianças é diferente daquela feita pelos adultos. Nesse sentido, a noção de reiteração nos ajuda a perceber como é feita a gestão do tempo pela criança e como ela o realiza no contexto de suas dinâmicas de socialização e de aprendizagem, no centro das culturas infantis.

O tempo como uma categoria social é algo que tem sentido variável, segundo contexto histórico e grupo social. Para Elias (1998), a ideia que cada ser humano faz do tempo é historicamente construída, socialmente aprendida, compartilhada e transformada. Assim, para o pensador:

O indivíduo não tem capacidade de forjar, por si só, o conceito de tempo. Esse, tal como a instituição social que lhe é inseparável, vai sendo assimilado pela criança à medida que ela cresce $[. .$.$] ao crescer, com efeito, toda criança vai-se familiari-$ zando com o "tempo" como símbolo de uma instituiçáo social cujo caráter coercitivo ela experimenta desde cedo (p. 13-14). [...] Uma criança que cresça numa dessas sociedades nacionais do século XX, industrializadas e submetidas a uma regulação temporal muito intensa, requer sete a nove anos para "aprender a dizer as horas”, isto é, para saber ler e interpretar o complexo sistema simbólico dos relógios e do calendário, além de adaptar a ele sua sensibilidade e seu comportamento (ELIAS, 1998, p. 112). 
O tempo escolar (PARENTE, 2006) como referência e métrica para o ofício de aluno (SARMENTO, 2011) é um bom exemplo desse caráter social do tempo imposto à criança como uma experiência compulsória à infância moderna, mesmo que a escola não seja uma realidade para todas as crianças. Ainda assim, aqui estamos falando do tempo quantificado elaborado pelo adulto para organizar os sentidos do tempo infantil; todavia, como pensar a percepção do tempo feito pelas crianças? A reiteração, eixo das culturas infantis, busca pensar tal questão no contexto da Sociologia da Infância. Desse modo, como evidencia Sarmento (2005, p. 375), por meio dos mecanismos e de recursos de simbolização e ação sobre o vivido que viabilizam a reiteração como o brincar, desenhar, contar histórias, por exemplo, a criança

funde os tempos presente, passado e futuro, numa recursividade temporal e numa reiteraçáo de oportunidades que é muito própria da sua capacidade de transposição no espaço-tempo e de fusão do real com o imaginário (Walter Benjamin, por exemplo, tem páginas admiráveis sobre esta capacidade de transmutaçáo infantil, cf. Benjamin, 1992). A alteração da lógica formal não significa que as crianças tenham um pensamento ilógico. Pelo contrário, essa alteração, estando patente na organização discursiva das culturas da infância (especialmente no que respeita ao jogo simbólico), é coexistente com uma organização lógico-formal do discurso, a qual permite que a criança simultaneamente "navegue entre dois mundos" — o real e o imaginário - explorando as suas contradiçóes e possibilidades (SARMENTO, 2005, p. 375).

A reiteração, portanto, é o conceito que ajuda a entender o mecanismo de gestão do tempo infantil feito pela criança. É um tempo afetivo e carregado de mecanismos sociolinguísticos de significação da vida, aprendidos no contato com a sociedade e mediado pelos produtos culturais de seu meio. Ao se constatar a complexidade da estrutura de funcionamento da reiteraçáo — mesmo porque defini-la serve apenas a fins didáticos, pois seu funcionamento se dá em concomitância com os outros eixos que definem atualmente o corpo conceitual de cultura da infância —, Sarmento argumenta a necessidade de estudos interdisciplinares para estruturar um campo teórico reflexivo que dê mais substância às pesquisas que tenham por objetivo abordar a gestão do tempo infantil feito pela criança a partir da Sociologia da Infância.

Nesse sentido, a Sociologia da Infância não apenas está aberta a diferentes teorias e abordagem, no seu interior - conforme veremos - como está consciente de que não conseguirá cumprir seu programa teórico se não se abrir determinantemente a um trabalho teórico interdisciplinar que contribua para impedir uma visão fragmentária de criança e que seja sustentado numa superação de dicotomias tradicionais, profundamente redutoras 
da compreensão da infância. [...] [Assim, sugere então o autor, estudar] A filosofia, e os contributos decisivos de W. Benjamin (1992) para análise da temporalidade recursiva da infância, prolongada na reflexão de Agamben (2005) sobre a criança do tempo e o contínuo processo de ampliação do mundo e das significaçóes pela redescoberta da linguagem (SARMENTO, 2013, p. 21-22).

Podemos avançar na direção de uma ideia de cultura da criança em Benjamin $(2002$; 2013; 2015) (BOLLE, 1984), mais especificamente sobre o aspecto que nos interessa, que é a reiteração. Como vimos, as culturas infantis configuram-se como algo amplo, no qual a criança tem a possibilidade de ressignificar o mundo e compartilhar tais processos de significação por meio da ação infantil. Seria a criação de uma zona limiar (BARRENTO, 2012; 2013; SANCHES; SILVA, 2018b) pela criança. Esse limiar envolve o mundo adulto em uma relação de aproximação e distanciamento e cujo resultado final, segundo o pensador, é a criação de um mundo pequeno no grande (BENJAMIN, 2002). Assim como a Sociologia da Infância, Benjamin (2002) destaca as funçóes da linguagem e do brincar nesse processo, pois é por meio delas que a criança incorpora, reinterpreta e narra o mundo ao seu modo, e afirma:

O adulto, ao narrar uma experiência, alivia o seu coração dos horrores, goza duplamente uma felicidade. A criança volta a criar para si todo o fato vivido, começa mais uma vez do início. Talvez resida aqui a mais profunda raiz do duplo sentido nos "jogos" alemães: repetir o mesmo seria o elemento verdadeiramente comum. A essência do brincar não é um "fazer como se", mas um "fazer sempre de novo", transformação da experiência comovente em hábito. Comer, dormir, vestir-se, lavar-se devem ser inculcados no pequeno irrequieto de maneira lúdica, com o acompanhamento do ritmo dos versinhos. O hábito entra na vida como brincadeira, e nele, mesmo em suas formas mais enrijecidas, sobrevive até o final um restinho de brincadeira. Formas petrificadas e irreconhecíveis de nossa primeira felicidade, de nosso primeiro terror, eis o que são os hábitos. E mesmo o pedante mais insípido brinca, sem o saber, de maneira pueril, não infantil, brinca ao máximo quando é pedante ao máximo. Acontece apenas que ela não se lembrará de suas brincadeiras; somente para ele uma obra como essa permaneceria muda. Mas quando um poeta moderno diz que para cada um existe uma imagem cuja contemplação o mundo inteiro submerge, para quantas pessoas essa imagem náo se levanta de uma velha caixa de brinquedos? (BENJAMIN, 2002, p. 101-102).

Dessa maneira, reiteração, como recurso de gestão do tempo pela criança, permite a criação de um lugar operacional entra a fantasia e o real, que libera a ação da criança e, assim, facilita que ela tenha experiências formativas nas relaçóes 
dela com o ambiente social. Ao repetir no brincar os fatos vividos, a criança organiza suas percepçóes qualitativa e quantitativa do tempo. Por meio da reiteração, a criança realiza uma temporalidade de experimentaçáo do mundo.

\section{Notas}

1. Durante o doutorado sanduíche (CAPES Processo: BEX 7915/14-4), realizado na École des Hautes Études en Sciences Sociales, Paris, o proponente deste artigo teve a oportunidade de conhecer um pouco dos meandros da educação escolar francesa e o modo como essa sociedade entende a participação das crianças nas comunidades. Há um princípio de tentar a inserção da infância em todos os espaços possíveis a ela no cotidiano social das famílias e dos núcleos sociais frequentados por elas. A cidade demonstra isso pela arquitetura e pelo planejamento urbanístico que contempla em seus micros detalhes a presença sensível das crianças com ambientes onde a dimensão lúdica é elemento essencial da composição urbana. Há para elas espaços totalmente adaptados com a finalidade de melhorar a experiência de socialização das crianças, tais como museus sensoriais e convencionais para crianças, parques, equipamentos de lazer, espaço no transporte público, espaço reservado nos bares e restaurantes, enfim, nos ambientes coletivos onde uma família possa frequentar com seus filhos. Esses pequenos gestos inscrevem a criança e a construçâo de sua corporeidade, de sua subjetividade, de modo muito forte na sociedade, afirmando sua existência como ator social e responsabilizando a comunidade em assegurar os direitos fundamentais das crianças.

2. Com o intuito de referenciar o pensador brasileiro que inaugurou as primeiras reflexôes brasileiras sobre a ideia de cultura infantil, gostaríamos de sugerir a leitura do ensaio: FERNANDES, 2004.

3. Os instrumentos do brincar são todos os objetos, os utensílios e até o próprio corpo ao serem empregados no ambiente das brincadeiras criados pelas crianças (RICHTER; VAZ, 2005) em uma perspectiva de ampliar as possibilidades de expressar, simbolizar, criar, recriar, reiterar por meio dos objetos com que brincam (SANCHES; SILVA, 2018b).

\section{Referências}

ARIÉS, P. História Social da Criança e da Família. 2. ed. Rio de Janeiro: Guanabara, 1981. BARRENTO, J. Limiares sobre Walter Benjamin. Florianópolis: Ed. da UFSC, 2013.

BARRENTO, J. Walter Benjamin: limiar, fronteira e método. Olho d'água, São José do Rio Preto, v. 4, n. 2, p. 41-51, jul./dez. 2012.

BENJAMIN, W. A hora da criança: narrativas radiofônicas. Rio de Janeiro: Nau, 2015.

BENJAMIN, W. Reflexóes: a criança, o brinquedo e o brincar, a educação. São Paulo: Duas Cidades; 34, 2002.

BENJAMIN, W. Rua de máo única: Infância berlinense: 1900. Belo Horizonte: Autêntica, 2013. 
BOLLE, W. Walter Benjamin e a cultura da criança. In: BENJAMIN, W. Reflexóes: a criança, o brinquedo e o brincar, a educação. São Paulo: Summus, 1984. p. 13-16.

BROUGÈRE, G. A criança e a cultura lúdica. In: KISHIMOTO, T. M. (org.). O brincar e suas teorias. São Paulo: Pioneira Thomson Learning, 2002. p. 19-32.

COHN, C. Antropologia da criança. Rio de Janeiro: Jorge Zahar, 2005.

CORSARO, W. A. A Reprodução Interpretativa no Brincar ao "Faz de Conta" das Crianças. Educaçáo, Sociedade \& Culturas, Porto, n. 17, p. 113-134, 2002.

ELIAS, N. Sobre o tempo. Rio de Janeiro: Jorge Zahar, 1998.

FERNANDES, F. As "trocinhas" do Bom Retiro. Pro-Posiçóes, v. 15, n. 1 (43), p. 229-250, 2004.

MAUSS, M. Três observações sobre a sociologia da infância. Pro-Posiçóes, Campinas, v. 21, n. 3 (63), p. 237-244, set./dez. 2010. http://dx.doi.org/10.1590/S0103$\underline{73072010000300014}$

PARENTE, C. da M. D. A Construçáo dos Tempos Escolares: possibilidades e alternativas plurais. 2006. 215 f. Tese (Doutorado em Educação) - Universidade Estadual de Campinas, Campinas, 2006.

QUINTEIRO, J. Sobre a emergência de uma sociologia da Infância: contribuiçóes para o debate. Perspectiva, v. 20, n. esp., p. 137-162, 2002. https://doi.org/10.5007/\%25x

RICHTER, A. C.; VAZ, A. F. Corpos, saberes e infância: um Inventário para estudos sobre a Educaçáo do corpo em ambientes Educacionais de 0 a 6 anos. Revista Brasileira de Ciência do Esporte, Campinas, v. 26, n. 3, p. 79-93, maio 2005.

SANCHES, E. O.; SILVA, D. J. da. Eu vô lá ontem, papai! Experiência e culturas infantis: reflexôes sobre infância e temporalidade recursiva. Educaçáo e Sociedade, Campinas, v. 37, n. 135, p. 497-516, abr.-jun. 2016. http://dx.doi.org/10.1590/ES0101$\underline{73302016138082}$

SANCHES, E. O.; SILVA, D. J. da. Infância e Coleção: experiência e profanação em Walter Benjamin. Educaçáo e Sociedade, Campinas, v. 39, n. 143, p. 379-396, 2018a. http://dx.doi.org/10.1590/es0101-73302018176460

SANCHES, E. O.; SILVA, D. J. da. Infância e limiar em Walter Benjamin. Perspectivas, Florianópolis, v. 36, n. 3, p. 992-1006, 2018b. http://dx.doi.org/10.5007/2175795X.2018v36n3p992

SARMENTO, M. J. A reinvenção do ofício de criança e de aluno. Atos de Pesquisa em Educação, v. 6, n. 3, p. 562-571, set./dez. 2011. http://dx.doi.org/10.7867/18090354.2011v6n3p581-602

SARMENTO, M. J. A Sociologia da infância e a sociedade contemporânea: desafios conceituais e praxeológicos. In: ENS, R. T.; GARANHANI, M. C. (orgs.), Sociologia da infância e a formaçáo de professores. Curitiba: Champagnat Editora, 2013. p. 13-46.

SARMENTO, M. J. As culturas da infância nas encruzilhadas da $2^{\text {a }}$ modernidade. In: SARMENTO, M. J.; CERISARA, A. B. (orgs.). Crianças e miúdos: perspectivas sócio-pedagógicas da infância e educação. Porto: Asa, 2004. p. 9-34. 
SARMENTO, M. J. Geraçóes e Alteridade: interrogaçóes a partir da Sociologia da Infância. Educaçáo e Sociedade, Campinas, v. 26, n. 91, p. 361-378, maio/ago. 2005. http://dx.doi.org/10.1590/S0101-73302005000200003

SARMENTO, M. J. Imaginário e culturas da infância. Cadernos de Educaçáo, Pelotas, v. 12, n. 21, p. 51-69, 2003. http://dx.doi.org/10.15210/caduc.v0i21.1467

SARMENTO, M. J. Mapa de Conceitos na área de estudos da Sociologia da Infância. Revista Zero-a-Seis. Florianópolis, v. 8, n. 14, p. 1-8, 2006.

SARMENTO, M. J.; MARCHI, R. de C. Radicalização da infância na segunda modernidade: para uma Sociologia da Infância crítica. Configuraçóes, Minho, n. 4, p. $91-113,2008$.

SARMENTO, M. J.; PINTO, M. As crianças e a infância: definindo conceitos, delimitando o campo In: PINTO, M.; SARMENTO, M. J. (orgs.). As Crianças: Contextos e Identidades. Braga: Centro de Estudos da Criança, Universidade do Minho, 1997. p. 7-30.

SIROTA, R. Emergência de uma sociologia da infância: evolução do objeto e do olhar. Cadernos de Pesquisa, n. 112, p. 7-31, mar. 2001. http://dx.doi.org/10.1590/S0100$\underline{15742001000100001}$

\section{SOBRE O AUTOR}

Eduardo Oliveira Sanches é doutor em Educação. Professor do curso de Pedagogia da Universidade Estadual de Maringá (UEM).

Recebido em 25 de maio de 2018.

Aceito em 04 de fevereiro de 2019. 